RESEARCH PAPER

\title{
The US tobacco control community's view of the future of tobacco harm reduction
}

\author{
K E Warner, E G Martin
}

Tobacco Control 2003;12:383-390

See end of article for authors' affiliations

.....................

Correspondence to: Kenneth E Warner Department of Health Management \& Policy, School of Public Health, University of Michigan, 109 South Observatory Road, Ann Arbor Michigan 48109-2029, USA; kwarner@umich.edu

Received 27 May 2003 Accepted 18 September 2003
Objective: Tobacco harm reduction (THR) has garnered recent attention due to the introduction of novel nicotine delivery products ostensibly intended to reduce risk for inveterate cigarette smokers. This study evaluates the grassroots tobacco control community's knowledge, opinions, and beliefs about THR.

Design: A web/mail survey conducted in October and November 2002, with a telephone survey of a sample of non-respondents.

Subjects: The 2833 US based registrants for the 2001 National Conference on Tobacco or Health. Main outcome measures: Respondents' awareness of THR, perception of its importance, support for regulation, and perception of which THR products should be recommended to inveterate cigarette smokers.

Results: $70 \%$ of respondents were aware of THR but respondents had low recognition of specific products at the forefront of the debate, such as Swedish snuff. Half believe THR will reduce smoking cessation and cause nicotine experimentation by children; $63 \%$ anticipate unintended adverse side effects. More expect THR to have a negative than a positive impact on health. Large majorities support government regulation of THR and conventional tobacco products, but fewer than $30 \%$ expect legislation regulating either. Most would recommend nicotine patches $(76 \%)$ and gum $(70 \%)$ to inveterate smokers, but no other product was supported by a majority. Scientists are more supportive of THR than activists, while respondents focusing on national/international issues are more supportive than those concentrating on local/state issues.

Conclusions: Many members of the US tobacco control community are unaware of the THR "movement", while others possess only rudimentary familiarity with it. If and as THR achieves an increasingly prominent role on the tobacco-or-health scene, this community will have to become educated about THR, and be prepared to advocate for regulatory policies that will maximise the potential for positive outcomes. The potential for negative outcomes remains significant.
D riven by everything from arguments about human rights $^{1}$ to concerns about market forces, ${ }^{2}$ a debate has arisen as to whether it is possible-and if possible, desirable- to try to reduce the toll of smoking through "harm reduction". Tobacco harm reduction (THR) envisions encouraging cigarette smokers who cannot or will not quit to adopt alternative nicotine or tobacco products that, compared to continued smoking, may reduce their risk of disease and premature death. ${ }^{34}$ Public health interest in this possibility derives from the fact that, although smoking prevalence has declined in many developed countries for nearly 40 years, the rate of decline is frustratingly slow, ${ }^{5}$ and the consequent death toll remains frighteningly high. ${ }^{6}$

Interest in the topic of THR emerged in the academic literature relatively recently. ${ }^{78}$ Over the past few years, the subject has garnered considerable attention among leaders in smoking cessation and tobacco control in the developed nations.. ${ }^{10}$ But what do the "foot soldiers" of the war against tobacco-the grassroots activists, the local programme managers-think? To date, no one has assessed their understanding of or interest in harm reduction, nor their opinions on its desirability as a tobacco control strategy. Clearly, their beliefs and involvement will play a central role in any future attempt to promulgate, or to discourage, the notion that potentially less harmful nicotine and tobacco products should be deemed a viable alternative for inveterate cigarette smokers. To determine the opinions of these "foot soldiers" in one country, we surveyed over 2800 individuals involved in tobacco control in the USA.

\section{METHODS}

There is no "registry" of individuals involved in tobacco control in the USA. However, there is an annual National Conference on Tobacco or Health that draws close to 3000 people involved in tobacco control, as many active members of the US tobacco control community as any identifiable group we could imagine. We selected the 2833 US based registrants for the 2001 National Conference as a convenience sample. We purchased an electronic file of mailing addresses from the conference organisers and contracted with MSInteractive, a survey research firm, for assistance with web programming and data collection. We entered email addresses for 2051 (72.4\%) from the published list of registrants into the address file. We could not obtain email addresses for attendees who did not submit all of their contact information to conference organisers or registered late for the meeting and were not listed in the directory.

We developed a web based survey instrument, with a corresponding paper based mail survey for individuals who did not respond on the internet. The survey included questions pertaining to: (1) awareness of THR; (2) perception of its present and future importance in tobacco control; (3) support for regulatory policies pertaining to THR and conventional tobacco products, and assessment of whether Congress will pass legislation requiring regulation; and (4) perception of which, if any, THR products should be recommended by health care practitioners to inveterate smokers. The survey can be viewed at: http:// www.sph.umich.edu/ kwarner/thrsurvey.pdf. 
The web survey was created with mrInterview 1.1 software. ${ }^{11}$ Where the order of closely related questions might affect responses, we randomised their order of appearance (for example, agreement or disagreement with various government regulatory policies). For the paper survey, we adopted the most neutral ordering, such as alphabetical order. Eight colleagues piloted the web based survey. All data were collected in a seven week period beginning 2 October 2002. The survey closed on November 19, the first day of the 2002 National Conference, where one of the authors (KEW) was speaking on THR.

Initially, an email invitation was sent to all attendees with an email address. Each message explained the survey contents, noted the funding source (the Robert Wood Johnson Foundation), and contained a unique link to the web site, with an embedded computer generated participant identification number. Two reminder emails were sent to non-respondents over the next two weeks. Letters containing the main web link and a unique identification number were mailed to respondents without email addresses.

After three weeks, the paper based survey was mailed to all participants who had not accessed the web site. These materials also contained identification numbers for tracking. The survey was followed with a reminder/thank you postcard during week 4, and, for those who had not replied, another copy of the survey during week 5 . A final email reminder was sent six weeks after the survey was launched.

A random sample of 200 non-respondents was selected for telephone follow up starting in January 2003 to assess their reasons for not participating and their familiarity with THR. Telephone numbers for 133 were data entered from the published list of registrants. Contact information for 51 was found from the next year's (2002) National Conference directory or through an online search. No information could be obtained for 16 individuals $(8 \%)$. Up to eight attempts were made to contact each participant.

Data from the survey were compiled into one file and analysed using SAS 8.2 (SAS Institute Inc, Cary, North Carolina, USA). For most questions, we evaluated the responses of all respondents. For two questions, only respondents familiar with THR replied (for example, their sources of prior knowledge of the subject). For the majority of questions, we also studied the replies of: (1) scientists and researchers compared to advocates and activists; and (2) respondents focusing on local and/or state concerns compared with those with primarily national and/or international interests. In each case, individuals selecting both categories (multiple responses were permitted) were excluded from the analysis. This allowed examining the responses of, for example, the "pure" scientists versus those of the "pure" activists, omitting individuals in both groups. We also studied differences in responses by education level but report few findings since education correlated highly with science versus activism and geographic level locus of interest. We developed logistic regression models to assess multicollinearity in determining associations with THR familiarity and various attitudes toward and beliefs about THR. As findings did not add much insight to the results from the simple correlations, we present results only from the latter.

Many of the opinion questions were constructed as five point Likert scales, with response ranges such as "strongly agree" to "strongly disagree". Some of these categories have been collapsed in the data analysis (for example, combining "strongly agree" with "agree"). Three questions had three point scales.

We performed all statistical analyses both with and without "unsure" responses. We did not see many qualitative differences in results, and, with one exception, report only the findings that do not contain "unsure" responses. The exception was that when we analysed responses by THR familiarity, we categorised individuals indicating they were "unsure" whether they had heard about THR as not having heard of it. Rarely employed, the "rather not answer" option was removed from all analyses. $\chi^{2}$ Tests were used to evaluate the significance of all differences in findings across respondent types. The significance level was set at 0.05. Although individual significance test results are not presented in the Results section below, all comparative statements in that section are significant at $\mathrm{p}<0.05$ (for example, "Scientists are more likely than activists to believe $X^{\prime \prime}$ ).

To calculate the response rate, we used the telephone survey to assess the percentage of non-respondents ineligible to participate $(45.9 \%$ of the individuals successfully contacted) due to inaccurate addresses, foreign addresses, unavailability at the listed address during the time of the survey, or not attending the 2001 National Conference. Using this as an estimate of ineligibility among non-respondents, the adjusted response rate was $67.1 \% .^{12}$ All responses, including those that were incomplete, were included in the response rate calculation. However, the sample size presented in the tables reflects individuals who answered at minimum the first question; $93.1 \%$ of respondents completed the survey.

\section{RESULTS}

Table 1 presents descriptive statistics characterising the mix of respondents by various demographic variables and tobacco control roles. Most (70\%) are female. Approximately a fifth are from minority groups. A third work for government, the vast majority at the state or local level. Slightly over an eighth work in universities, while a comparable number are employed by a tobacco control organisation. Nearly a 10th work for one of the major voluntary health organisations (for example, the American Cancer Society). For four fifths, their involvement in tobacco control is integrally related to their paid employment. When asked about the nature of their involvement, with multiple responses permitted, the most common responses were programme management (35\%), education $(34 \%)$, and activism (28\%). Approximately a fifth have programme staff positions, while a similarly sized group are researchers or scientists.

Most of the respondents ( $71 \%$ ) have engaged in significant volunteer activities related to tobacco control in the past year. Nearly three quarters focus some or all of their tobacco control energies on youth and adolescents. In contrast, just over an eighth focus some of their work on the elderly. Large percentages also devote efforts to women and minorities. The geographic locus of respondents' tobacco control efforts (with multiple answers permitted) is primarily at the state $(62 \%)$ and local level (66\%); $29 \%$ work on national tobacco control issues and $8 \%$ on international issues.

\section{Awareness of THR}

Overall, $70 \%$ of respondents were familiar with the term "tobacco harm reduction" before receiving the survey (table 2). (Note that, to assess familiarity-and only for this purpose-we combined "unsure" with negative responses.) Researchers/scientists (hereafter "scientists") were far more likely to be familiar with THR (87\%) than were advocates/ activists (hereafter "activists") (67\%) (p<0.001). Similarly, respondents focused on national/international tobacco control issues were more likely $(81 \%)$ than those emphasising state/local issues $(66 \%)$ to be familiar with THR $(p<0.001)$. (There is substantial correlation between the categories: scientists are more likely to focus on national and international issues, while activists concentrate on local issues.) There was a clear educational gradient in awareness of THR (not shown in the table), ranging from $82 \%$ for doctoral 


\begin{tabular}{|c|c|c|}
\hline Characteristic or role & Category & $\%$ \\
\hline Age & $\begin{array}{l}\leqslant 30 \\
31-50 \\
>50\end{array}$ & $\begin{array}{l}19.7 \\
55.6 \\
24.7\end{array}$ \\
\hline Female sex & & 70.1 \\
\hline Race/ethnicity $\dagger$ & $\begin{array}{l}\text { White, non-Hispanic } \\
\text { African American } \\
\text { Hispanic } \\
\text { Asian/Pacific Islander } \\
\text { American Indian/Alaskan Native } \\
\text { Other }\end{array}$ & $\begin{array}{r}80.5 \\
9.0 \\
5.1 \\
4.2 \\
2.7 \\
1.0\end{array}$ \\
\hline Education & $\begin{array}{l}<\text { Masters degree } \\
\text { Masters degree } \\
\text { Doctoral degree }\end{array}$ & $\begin{array}{l}40.9 \\
40.5 \\
18.6\end{array}$ \\
\hline Employerł & $\begin{array}{l}\text { Local government } \\
\text { State government } \\
\text { Federal government } \\
\text { College or university } \\
\text { Medical care delivery org. } \\
\text { Major voluntary health org. } \\
\text { Tobacco control org. } \\
\text { Other (including self employed, 3.1\%, } \\
\text { and not employed, } 0.9 \% \text { ) }\end{array}$ & $\begin{array}{r}12.9 \\
16.0 \\
4.7 \\
13.7 \\
5.8 \\
9.3 \\
13.5 \\
24.0\end{array}$ \\
\hline $\begin{array}{l}\text { Tobacco control involvement } \\
\text { integrally related to paid employment }\end{array}$ & & 82.1 \\
\hline $\begin{array}{l}\text { Principal involvements with } \\
\text { tobacco issuest }\end{array}$ & $\begin{array}{l}\text { Advocate/activist } \\
\text { Educator } \\
\text { Medical professional counselling } \\
\text { Programme admin/manager } \\
\text { Programme staff } \\
\text { Researcher/scientist } \\
\text { Other }\end{array}$ & $\begin{array}{r}27.9 \\
33.7 \\
6.8 \\
35.3 \\
21.3 \\
17.8 \\
12.4\end{array}$ \\
\hline Significant volunteer efforts $\dagger$ & $\begin{array}{l}\text { Any } \\
\text { Local tobacco control coalition } \\
\text { State based tobacco control coalition } \\
\text { National tobacco control organisations } \\
\text { Smokers' rights organisations }\end{array}$ & $\begin{array}{r}71.0 \\
42.3 \\
36.9 \\
55.6 \\
0.8\end{array}$ \\
\hline $\begin{array}{l}\text { Demographic focus of tobacco } \\
\text { control efforts } \dagger\end{array}$ & $\begin{array}{l}\text { Youth/adolescents } \\
\text { Elderly } \\
\text { Women } \\
\text { Minorities } \\
\text { General population }\end{array}$ & $\begin{array}{l}73.5 \\
14.0 \\
36.0 \\
45.4 \\
67.9\end{array}$ \\
\hline $\begin{array}{l}\text { Geographic level of focus of } \\
\text { tobacco control efforts } \dagger\end{array}$ & $\begin{array}{l}\text { Local } \\
\text { State } \\
\text { National } \\
\text { International }\end{array}$ & $\begin{array}{r}66.3 \\
62.0 \\
29.2 \\
7.7\end{array}$ \\
\hline \multicolumn{3}{|c|}{$\begin{array}{l}\text { *Due to attrition and exclusion of "unsure" and "rather not answer" responses, the number of cases included in } \\
\text { each calculation may be smaller. } \\
\text { tFigures sum to }>100 \% \text { because respondents were permitted to select all answers that apply. } \\
\text { fFigures do not add to } 100 \% \text { because of rounding. }\end{array}$} \\
\hline
\end{tabular}

trained respondents to $62 \%$ for respondents possessing less than a masters degree.

Of those familiar with THR, 59\% of respondents first heard of THR within the previous two years, and $91 \%$ within the previous five years. The leading sources of information on THR (with multiple responses permitted) were scientific conferences $(64 \%)$, scientific and professional journals $(61 \%)$, and conversations with non-medical colleagues $(50 \%)$. Conferences and journals were more likely to be sources of information for scientists $(p<0.001)$ and for respondents focused on national/international issues $(\mathrm{p}<0.01)$. Activists were more likely than scientists to have derived information from the media $(p<0.001)$.

When asked how much attention THR receives within the field of tobacco control, $43 \%$ of all respondents answered from "a fair amount" to "a great deal". However, only 5\% answered "a great deal". Ten years from now, 83\% expect at least "a fair amount" of attention, with nearly a third answering "a great deal" ("a great deal" not shown in table alone). Differences within groups reflected differences in initial familiarity.

We queried respondents about their awareness of 19 current or previous potential harm reduction products by brand name, including three made up names (responses not shown in the table). Very few respondents selected the three fake products (from well under $1 \%$ for "Hitex" to $6 \%$ for "Viva"). Only one actual product-Likatine, a now banned nicotine lollipop formulated by a pharmacy-received less recognition $(3 \%)$ than any of the fake products. Five of the 16 real products were recognised by a majority of respondents, with two pharmaceutical products (Nicoderm and Nicorette) recognised by virtually everyone (94\% and $96 \%$, respectively).

Only two tobacco industry products were recognised by a majority of respondents: Eclipse (53\%), RJ Reynolds' cigarette-like product that primarily heats rather than burns its contents, and Omni $(50 \%)$, Vector Tobacco's cigarette that yields reduced quantities of three carcinogens. Over a third 
Table 2 Respondents' awareness of tobacco harm reduction

\begin{tabular}{|c|c|c|c|c|c|c|c|}
\hline \multirow[b]{2}{*}{ Question } & \multicolumn{7}{|c|}{ Respondent category (number of respondents)* } \\
\hline & All (1473) & $\begin{array}{l}\text { Researcher/ } \\
\text { scientists (199) }\end{array}$ & $\begin{array}{l}\text { Activists/ } \\
\text { advocates } \\
\text { (338) }\end{array}$ & p Value & $\begin{array}{l}\text { National/ } \\
\text { international } \\
\text { (117) }\end{array}$ & $\begin{array}{l}\text { State/ } \\
\text { local } \\
(963)\end{array}$ & p Value \\
\hline $\begin{array}{l}\text { Familiar with "tobacco harm reduction" } \\
\text { before survey? (\% answering yes)† }\end{array}$ & 69.7 & 86.9 & 66.6 & $<0.001$ & 81.2 & 66.2 & 0.001 \\
\hline$\leqslant$ past year & 28.5 & 16.6 & 32.1 & $<0.001$ & 22.5 & 33.6 & 0.026 \\
\hline$>1, \leqslant 2$ years ago & 30.7 & 25.2 & 32.1 & & 28.1 & 32.6 & \\
\hline$>2, \leqslant 5$ years ago & 31.9 & 43.6 & 26.3 & & 38.2 & 27.6 & \\
\hline$>5$ years ago & 8.9 & 14.7 & 9.6 & & 11.2 & 6.2 & \\
\hline \multicolumn{8}{|l|}{ Sources of THR information $\ddagger$} \\
\hline Scientific conferences & 64.1 & 80.5 & 54.4 & $<0.001$ & 74.7 & 58.8 & 0.004 \\
\hline Scientific or professional journals & 60.7 & 74.6 & 53.5 & $<0.001$ & 73.6 & 56.1 & 0.002 \\
\hline \multicolumn{7}{|l|}{ Conversations with medical professionals or } & 0.580 \\
\hline Conversations with non-medical colleagues & 49.6 & 52.1 & 57.6 & 0.278 & 56.3 & 46.6 & 0.089 \\
\hline Newspapers, magazines, television, or radio & 30.7 & 20.7 & 37.3 & $<0.001$ & 31.0 & 31.5 & 0.941 \\
\hline Tobacco industry reports and documents & 24.7 & 24.8 & 31.8 & 0.135 & 32.2 & 23.3 & 0.071 \\
\hline \multirow{2}{*}{$\begin{array}{l}\text { How much attention does THR receive within the } \\
\text { field of tobacco control now? (\% answering a fair } \\
\text { amount to a great deal/\% little or none) } \\
\text { How much attention will THR receive } 10 \text { years from } \\
\text { now? (\% answering a fair amount to a great deal/\% } \\
\text { little or none) }\end{array}$} & $42.9 / 57.1$ & $54.6 / 45.4$ & $36.4 / 63.6$ & $<0.001$ & $58.2 / 41.8$ & $\begin{array}{l}37.0 / \\
63.0\end{array}$ & $<0.001$ \\
\hline & $82.7 / 17.3$ & $88.3 / 11.7$ & $82.4 / 17.6$ & 0.084 & $87.2 / 12.8$ & $\begin{array}{l}80.7 / \\
19.3\end{array}$ & 0.106 \\
\hline \multicolumn{8}{|c|}{$\begin{array}{l}\text { "Sample sizes include all individuals who selected an answer that placed them in the relevant respondent category. Due to attrition and exclusion of "unsure" a } \\
\text { "rather not answer" responses, the number of cases included in each calculation may be smaller. } \\
\text { †Respondents answering "unsure" were categorised with those answering "no" for this one question. For all other questions, all "unsure" and "rather not } \\
\text { answer" responses were excluded from the calculations. } \\
\text { †Asked of those who responded "yes" to the first question. }\end{array}$} \\
\hline
\end{tabular}

had heard of Ariva Cigalets, a compressed tobacco lozenge produced by Star Scientific, and just under a fourth were aware of Accord, a Philip Morris product. Of products introduced years before the label "harm reduction" was in vogue, only Premier, the precursor to Eclipse, was recognised by a significant number of respondents (30\%).

With one exception, none of the other products was recognised by as many as a fifth of respondents. This group included snus, the Swedish snuff regarded by many experts as the pre-eminent natural experiment in THR ${ }^{13}$; two novel forms of smokeless tobacco in the USA with reduced nitrosamines (Exalt and Revel); and two early generation products, Favor, a nicotine inhaler, and Next, a very low nicotine cigarette. The exception was nicotine water, recognised by $72 \%$ of respondents. In general, respondents previously familiar with THR, scientists, and respondents focusing on national/international issues were more likely to recognise the novel tobacco industry products.

\section{Importance of THR}

Ten years from now, THR is expected to have a smaller rather than a larger role in decreasing tobacco related health risks than will any of the three traditional pillars of tobacco control: prevention of initiation, cessation, and reduction of environmental tobacco smoke (ETS) (table 3). However, a quarter of respondents believe the role of THR will exceed that of cessation and reduction of ETS. In those two instances, a majority of respondents expect the role of THR to be comparable or larger.

Approximately half of respondents believe that THR will reduce the rate of smoking cessation, and a like number expect that THR will cause many children who would not have smoked to experiment with new nicotine containing products. In both instances, however, a third of respondents disagree. Almost two thirds anticipate that new products will produce unintended negative effects on health, with only 13\% disagreeing. Activists are more likely than scientists to anticipate increases in children's use of nicotine containing products $(\mathrm{p}<0.001)$.
Assuming no restriction on the future production and marketing of THR products, more than twice as many respondents believe that THR will have a negative than a positive impact on Americans' health 20 or more years hence. However, a quarter of respondents expect that health will benefit. Activists have a greater expectation of harm than do scientists $(\mathrm{p}<0.05)$.

Respondents' reactions to THR might well be influenced by experience with an earlier generation of innovative cigarettes advertised as less harmful than the conventional product and therefore an alternative to quitting: low tar and nicotine $(\mathrm{t} / \mathrm{n})$ cigarettes, marketed heavily beginning in the early $1970 \mathrm{~s} .{ }^{14}$ As such, we wanted to assess respondents' beliefs regarding the net health impacts of low $\mathrm{t} / \mathrm{n}$ cigarettes. A large majority believed that smoking low $\mathrm{t} / \mathrm{n}$ cigarettes does not appreciably change individual smokers' health risks. However, a fifth concluded that low $\mathrm{t} / \mathrm{n}$ cigarettes increase risks, while only $10 \%$ believed they reduce risks. Two fifths of respondents believed that, collectively, Americans' health would have been better had low $t / n$ cigarettes never been marketed. Half observed no appreciable impact. Only $7 \%$ perceived that low $\mathrm{t} / \mathrm{n}$ cigarettes had improved the health of Americans.

\section{Regulatory policies regarding THR}

Respondents overwhelmingly supported all of the regulatory policy options listed in table 4 for both THR and conventional tobacco products. The least strongly supported policy option-excise taxation on all THR products scaled to anticipated risk-was favoured by just under two thirds, with only $17 \%$ opposed. In contrast, three quarters supported excise taxes for conventional tobacco products, with an eighth in opposition.

Respondents clearly do not expect Congress to pass legislation within the next five years that would regulate either THR or conventional tobacco products. In both instances, half rated the chances as unlikely. However, 23\% and $30 \%$, respectively, do consider it likely. 
Table 3 Respondents' perceptions of the future importance of tobacco harm reduction

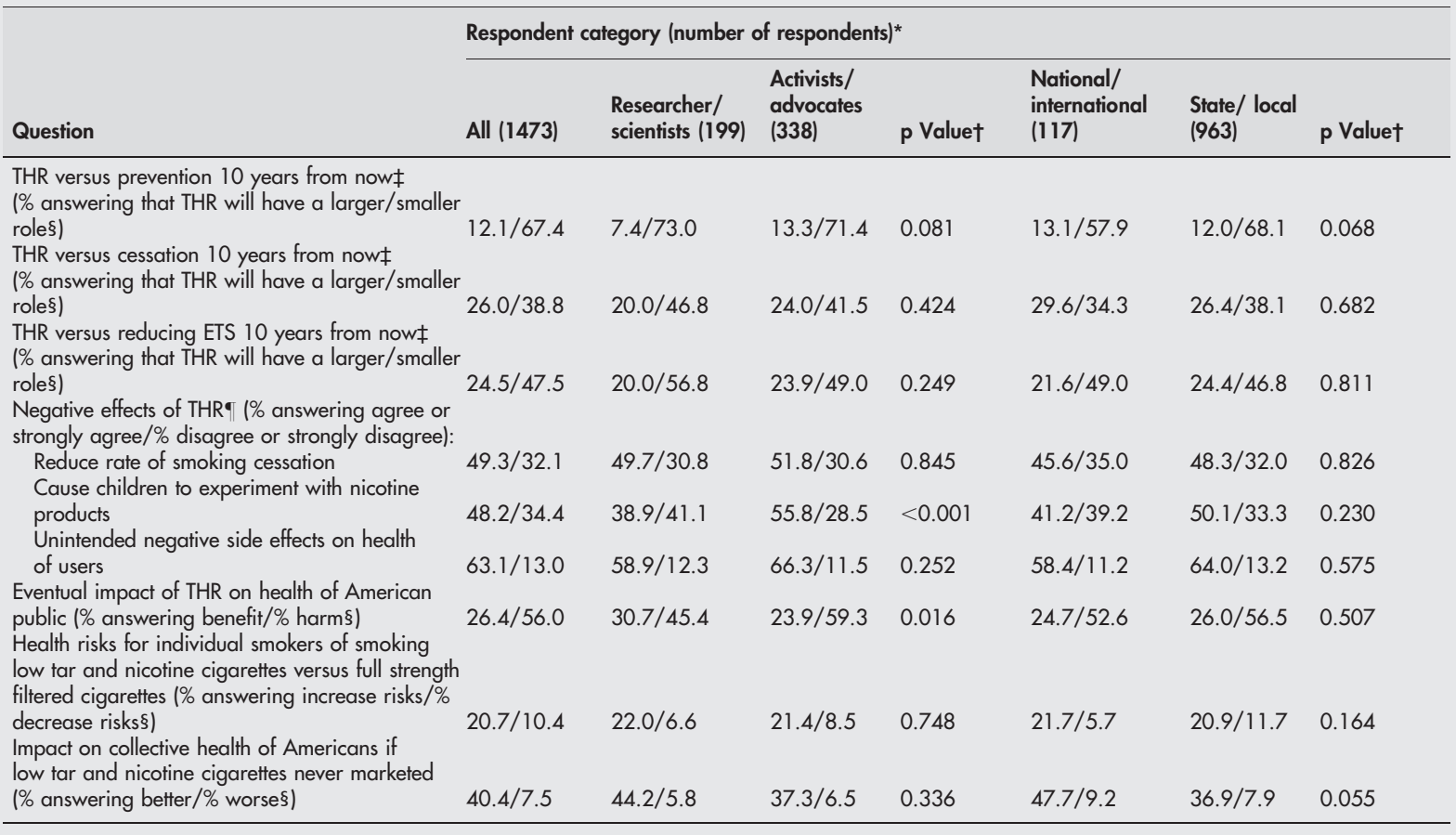

*Sample sizes include all individuals who selected an answer that placed them in the relevant respondent category. Due to attrition and exclusion of "unsure" and "rather not answer" responses, the number of cases included in each calculation may be smaller.

$t x^{2}$ test calculated as a $3 \times 2$ table, including the neutral responses (not shown above).

\#Entire question reads: "Ten years from now, how do you think tobacco harm reduction will compare to the following methods to decrease tobacco related health risks?"

§Percentages do not add to $100 \%$ because neutral responses have not been included in the table.

-Entire question reads: "Please indicate your level of agreement or disagreement with the following statements regarding potential negative consequences of harm reduction. (a) Harm reduction will reduce the rate of smoking cessation. (b) Harm reduction will cause many children who would not have tried smoking to experiment with new nicotine containing products. (c) New products will have unintended negative side effects on the health of the products' users (e.g. by introducing a new toxin)."

Table 4 Respondents' perceptions of the need for and likelihood of government regulation of THR and conventional tobacco products

\begin{tabular}{|c|c|c|c|c|c|c|c|}
\hline \multirow[b]{2}{*}{ Question } & \multicolumn{7}{|c|}{ Respondent category (number of respondents) ${ }^{*}$} \\
\hline & All (1473) & $\begin{array}{l}\text { Researcher/ } \\
\text { scientists } \\
\text { (199) }\end{array}$ & $\begin{array}{l}\text { Activists/ } \\
\text { advocates } \\
\text { (338) }\end{array}$ & p Valuet & $\begin{array}{l}\text { National/ } \\
\text { international } \\
\text { (117) }\end{array}$ & $\begin{array}{l}\text { State/ local } \\
(963)\end{array}$ & P Valuet \\
\hline \multicolumn{8}{|l|}{$\begin{array}{l}\text { Regulation of THR products (\% answering agree } \\
\text { or strongly agree/\% disagree or strongly disagree } \neq \text { ) }\end{array}$} \\
\hline Pre-marketing approval of health claims & $91.3 / 5.7$ & $91.2 / 5.7$ & $89.9 / 7.1$ & 0.840 & $89.5 / 7.9$ & $91.8 / 5.3$ & 0.532 \\
\hline $\begin{array}{l}\text { Product performance standards } \\
\text { Pre-marketing approval based on significant reduction }\end{array}$ & $87.2 / 7.8$ & $84.6 / 9.3$ & $86.6 / 9.0$ & 0.682 & $87.9 / 7.5$ & $88.0 / 7.6$ & 0.994 \\
\hline $\begin{array}{l}\text { in health risk (compared to conventional smoking) } \\
\text { Post-marketing surveillance, banning products found }\end{array}$ & $88.4 / 7.9$ & $84.7 / 9.7$ & $88.5 / 7.7$ & 0.418 & $81.8 / 12.7$ & $88.8 / 7.5$ & 0.102 \\
\hline to cause unacceptable health risks or attract children & $93.2 / 4.2$ & $92.8 / 4.6$ & $93.2 / 4.0$ & 0.940 & $88.7 / 5.2$ & $93.3 / 3.9$ & 0.139 \\
\hline Regulation of marketing techniques & $90.4 / 4.9$ & $89.6 / 5.7$ & $91.4 / 4.9$ & 0.782 & $86.5 / 7.2$ & $90.6 / 4.6$ & 0.359 \\
\hline Excise taxes tied to level of risk to user & $65.1 / 16.7$ & $65.1 / 18.6$ & $66.8 / 14.4$ & 0.782 & $65.0 / 17.5$ & $65.2 / 17.1$ & 0.995 \\
\hline $\begin{array}{l}\text { Likelihood of Congressional law authorising } \geqslant 1 \text { of } \\
\text { these methods of THR regulation within next } 5 \text { years }\end{array}$ & & & & & & & \\
\hline (\% answering likely $/ \%$ not likely $\ddagger$ ) & $22.9 / 54.8$ & $23.6 / 55.3$ & $27.2 / 51.9$ & 0.719 & $34.1 / 43.2$ & $21.3 / 55.8$ & 0.018 \\
\hline \multicolumn{8}{|c|}{$\begin{array}{l}\text { Regulation of conventional tobacco products (\% answering } \\
\text { agree or strongly agree/\% disagree or strongly disagree } \neq \text { ) }\end{array}$} \\
\hline Regulation of marketing techniques & $93.8 / 4.3$ & $95.4 / 3.6$ & $94.6 / 3.6$ & 0.761 & $85.3 / 8.6$ & $94.1 / 4.2$ & $<0.001$ \\
\hline Evaluation of safety & $94.0 / 4.1$ & $92.9 / 4.6$ & $94.6 / 3.6$ & 0.724 & $87.7 / 8.8$ & $94.8 / 3.3$ & 0.006 \\
\hline $\begin{array}{l}\text { Excise taxes tied to level of risk to user } \\
\text { Regulation of packaging (including size, design, }\end{array}$ & $75.2 / 13.0$ & $73.4 / 13.8$ & $72.5 / 14.4$ & 0.977 & $73.4 / 16.5$ & $76.3 / 13.1$ & 0.621 \\
\hline placement of warning) & $89.2 / 5.3$ & $90.7 / 5.2$ & $92.1 / 4.2$ & 0.767 & $80.5 / 9.7$ & $88.4 / 5.5$ & 0.057 \\
\hline $\begin{array}{l}\text { Gradually phase nicotine content of tobacco products } \\
\text { down to non-addicting levels }\end{array}$ & $77.5 / 10.1$ & $65.2 / 18.3$ & $81.2 / 9.1$ & $<0.001$ & $70.3 / 12.9$ & $79.6 / 9.0$ & 0.098 \\
\hline Likelihood of Congressional law authorising $\geqslant 1$ of these & & & & & & & \\
\hline within next 5 years (\% answering likely/\% not likely & $29.8 / 49.5$ & $26.7 / 57.8$ & $37.9 / 43.4$ & 0.008 & $36.0 / 46.0$ & $26.8 / 51.4$ & 0.149 \\
\hline
\end{tabular}


Table 5 Respondents' beliefs about whether health professionals should recommend THR products to smokers who cannot or will not quit

\begin{tabular}{|c|c|c|c|c|c|c|c|}
\hline \multirow[b]{2}{*}{ Question } & \multicolumn{7}{|c|}{ Respondent category (number of respondents)* } \\
\hline & All (1473) & $\begin{array}{l}\text { Researcher/ } \\
\text { scientists (199) }\end{array}$ & $\begin{array}{l}\text { Activists/ } \\
\text { advocates } \\
\text { (338) }\end{array}$ & p Valuet & $\begin{array}{l}\text { National/ } \\
\text { international } \\
(117)\end{array}$ & $\begin{array}{l}\text { State/ local } \\
\text { (963) }\end{array}$ & p Valuet \\
\hline \multicolumn{8}{|l|}{$\begin{array}{l}\text { For all items, results given as } \% \text { answering in } \\
\text { favour of recommending use } / \% \text { opposed } \neq\end{array}$} \\
\hline Cigarettes that heat but do not burn tobacco & $10.0 / 77.3$ & $6.7 / 81.7$ & $9.1 / 75.5$ & 0.425 & $14.3 / 71.4$ & $11.0 / 76.9$ & 0.487 \\
\hline Conventional smokeless tobacco products & $6.2 / 90.2$ & $4.7 / 90.0$ & $6.2 / 90.6$ & 0.404 & $8.5 / 83.0$ & $6.4 / 90.6$ & 0.008 \\
\hline Very low nitrosamine smokeless tobacco products & $11.0 / 81.1$ & $15.1 / 74.7$ & $9.6 / 83.2$ & 0.093 & $18.6 / 71.1$ & $10.0 / 83.2$ & 0.012 \\
\hline Nicotine patches & $75.8 / 17.5$ & $78.2 / 16.0$ & $74.5 / 18.9$ & 0.647 & $81.8 / 12.7$ & $74.4 / 18.4$ & 0.238 \\
\hline Tobacco lozenges & $39.3 / 48.0$ & $43.0 / 40.5$ & $33.3 / 54.8$ & 0.014 & $39.8 / 45.2$ & $39.4 / 49.0$ & 0.577 \\
\hline Cigarettes with $\geqslant 1$ carcinogen removed & $7.2 / 87.2$ & $4.4 / 87.4$ & $6.2 / 88.2$ & 0.375 & $10.1 / 87.2$ & $7.3 / 87.0$ & 0.275 \\
\hline Nicotine gum & $69.9 / 21.6$ & $76.1 / 14.9$ & $67.9 / 22.8$ & 0.002 & $81.1 / 12.6$ & $66.7 / 25.0$ & 0.007 \\
\hline Nicotine-free cigarettes & $17.2 / 72.4$ & $15.9 / 76.1$ & $16.2 / 70.2$ & 0.159 & $20.6 / 69.2$ & $17.1 / 72.9$ & 0.654 \\
\hline Low tar and nicotine cigarettes & $6.9 / 89.0$ & $2.1 / 91.7$ & $6.7 / 89.9$ & 0.023 & $8.0 / 87.5$ & $7.6 / 88.3$ & 0.970 \\
\hline
\end{tabular}

\section{Health practitioner recommendations of THR products to inveterate smokers}

With one exception, respondents strongly opposed health professionals' recommending use of any of the tobacco products, conventional or novel, by inveterate cigarette smokers (table 5). Opposition ranged from $72 \%$ for nicotine-free cigarettes to $90 \%$ for conventional smokeless tobacco. There was divided opinion concerning tobacco lozenges, although sentiment leaned against recommending them (48\% opposed, $39 \%$ in favour, with most opponents strongly opposed and most supporters only weakly supportive [strength of support not shown in table]). In contrast with the tobacco products, nicotine patches and gum were favoured by large majorities of respondents ( $76 \%$ and $70 \%$, respectively).

Activists were significantly more likely than scientists to oppose recommending several products for inveterate smokers, as were respondents focusing on state/local issues compared to those emphasising national/international concerns.

\section{Non-respondents}

We asked the non-respondents contacted after completion of the survey whether they were familiar with the term "tobacco harm reduction". Of those successfully contacted and eligible to participate in the survey, $40 \%$ indicated that they were not (or that they were "unsure"). Although higher than the $30 \%$ of respondents unfamiliar with the term at the outset, this difference is not significant owing to the small size of the non-respondent sample.

\section{DISCUSSION}

\section{Limitations}

There is no "registry" of tobacco control community "members", which calls into question whether our convenience sample of national conference attendees represents the broader tobacco control community. Further, do survey respondents fairly represent the conference attendees, since a third did not respond?

We believe that the conference participants constitute as good a representation of the US tobacco control community as is possible. However, participants are not fully representative. People who can afford to attend the conference may be more affluent or more likely to have an employer prepared to cover their costs of participation. As well, they may be more likely to be formally employed in the field and more heavily invested in their tobacco control role. Still, the sheer numbers involved ensure inclusion of a significant proportion of Americans who work at the grassroots level, as does the fact that respondents disproportionately focus on state and local tobacco control activities.

Although high for a contemporary, primarily web based survey, our response rate of $67 \%$ still raises the question of response bias. Within our sample of non-respondents, $40 \%$ were not familiar with the term THR, compared with $30 \%$ of respondents. Although not significant, this difference raises the possibility that respondents were more interested in our survey because more of them were aware of THR. As such, respondents' awareness of and opinions about THR may differ from those of the entire tobacco control community. However, we have captured the knowledge, opinions, and beliefs of a very large proportion of the tobacco control community. And although more respondents were aware of THR than were non-respondents, we do not know that their attitudes on and beliefs about the subject differ significantly. We think it unlikely that a $100 \%$ response rate would have changed our important qualitative findings.

Conference attendees almost certainly included some tobacco industry representatives and a few unpaid members of the "smokers' rights" community. However, none of the respondents indicated that they worked for tobacco companies, and only $11(0.8 \%)$ indicated smokers' rights organisation volunteer efforts. A larger number may have represented the industry. Clearly, industry related respondents' answers could differ significantly from those of tobacco control community members. However, the small proportionate representation of the industry at the conference (and in the survey) suggests that industry participation in the survey did not significantly bias responses.

As one further limitation of findings (but not of the survey itself), noted above, important correlations exist across the respondent subgroups. Despite several regression analyses, we have not ascertained whether geographic locus of interest (national/international versus local/state) or nature of involvement (science versus activism) is more important in the reported differences in initial awareness of THR.

\section{Implications of findings}

Although a majority of respondents were familiar with THR, a sizable minority were not. Given possible response bias and potential differences between conference registrants and those not attending, we think it highly likely that a substantial proportion of the entire grassroots tobacco control community is not aware of THR today. Suggestive evidence that it is not yet well understood lies in the large number of "unsure" answers (not reported above) to questions eliciting 
opinions on risks, policies, etc. Low recognition of products like snus, at the forefront of the international THR debate, is consistent with this proposition. For reasons discussed below, we consider the tobacco control community's limited awareness of THR troubling.

Respondents who do possess opinions worry about the future implications of THR. Most express concerns about potential unintended consequences. Respondents anticipate that THR will gain a significant foothold on the tobacco control scene over the next decade or more. THR is perceived as a significant, and likely threatening, factor in the tobacco control world of 2012. Further, while strongly supporting governmental regulation of both THR and conventional tobacco products, respondents do not anticipate Congressional legislation mandating such regulation.

Experience with an earlier generation of ostensibly less risky products-low $\mathrm{t} / \mathrm{n}$ cigarettes-supports this gloomy outlook. Presented in terms that look strikingly familiar to today's THR debate, low t/n cigarettes were marketed as an alternative to quitting for the concerned smoker. Much of the health community bought the message; leading medical textbooks advised physicians to encourage smoking patients who would not quit to switch to low $\mathrm{t} / \mathrm{n}$ cigarettes, fully a decade and a half after their introduction. ${ }^{15}{ }^{16}$ Today we know that the tobacco companies considered the low $\mathrm{t} / \mathrm{n}$ product a public relations device, rather than a truly less hazardous product. ${ }^{17}$ More than three decades after their introduction, low $\mathrm{t} / \mathrm{n}$ cigarettes have been implicated in a new form of lung cancer deeper in the lung, where more vigorous compensatory pulling on the cigarettes has brought the smoke. ${ }^{14}$ The advent of low $t / n$ cigarettes did not reduce the lethality of cigarettes and may have increased the cumulative toll of smoking by virtue of manufacturers' success in selling low $\mathrm{t} / \mathrm{n}$ cigarettes as an alternative to quitting. ${ }^{14}$ That this message has reached the tobacco control community is clear from survey answers. It is much less likely that the public-especially the smoking public — gets the message.

Not all forms of THR are made equal. Respondents strongly opposed recommending any tobacco product, conventional or novel, to cigarette smokers who cannot or will not quit. However, they overwhelmingly favoured substitution of nicotine pharmaceuticals, even if it meant long term, sustained use. The one product with significant numbers of supporters and opponents was "tobacco lozenges". We suspect confusion between a tobacco product, such as Ariva Cigalets, and the new Food and Drug Administration (FDA) approved pharmaceutical product, Commit.

Support of off-label use of FDA approved nicotine only products is consistent with the implications of the "risk-use equilibrium". ${ }^{18}$ This heuristic compares the health risks of products to individual consumers with the likelihood that they will generate substantial increased use of nicotine and tobacco products in the aggregate. With nicotine pharmaceuticals, risks to individuals are low, while population riskthe danger of widespread adoption by people who would otherwise have remained nicotine and tobacco-free-is minimal as well. The risk-use equilibrium also appears to recommend against combusted products, given their likely modest reduction in individual danger and considerable risk of significant "excess" adoption by the population.

Of great interest, however, is respondents' reaction to conventional and low nitrosamine smokeless tobacco products. The single strongest opposition to a product-90\%was registered for conventional smokeless tobacco, even greater than opposition to low $\mathrm{t} / \mathrm{n}$ cigarettes (89\%). Low nitrosamine smokeless tobacco also garnered substantial opposition $(81 \%)$. Low $\mathrm{t} / \mathrm{n}$ cigarettes are unequivocally more dangerous than smokeless tobacco and almost certainly more likely to maintain smoking. Smokeless tobacco definitely endangers health but likely poses an order of magnitude lower risk than does cigarette smoking. ${ }^{13}$ Very limited evidence of adverse health effects from Swedish snus suggests that the direct dangers associated with low nitrosamine smokeless products may be very modest. ${ }^{13}$ (The population effects could be considerable, however. ${ }^{4}$ ) Risking being labelled heretics, a few prominent members of the tobacco control community have come out in support of health professionals encouraging "hopelessly addicted" smoking patients to try switching to smokeless. ${ }^{19-21}$ There is a heated debate as to the wisdom of this recommendation, with no consensus within tobacco control's national and international leadership group." In the broader tobacco control community, in contrast, the consensus appears to be overwhelmingly negative.

The debate over tobacco harm reduction is almost certain to continue, fostered by the continued emergence of novel products. If one or more such products finds a significant market (none has to date), the intensity and visibility of concern about the issue is likely to increase substantially. So, too, will the stakes. THR is a novel concept within the US tobacco control community, widely regarded as of minor importance today. Yet that community clearly perceives a threat in the future. That threat might be mitigated through well designed Congressionally mandated regulation of both THR and conventional tobacco products, ${ }^{3}$ something survey respondents do not anticipate. The likelihood of such regulation will grow if and as the broader tobacco control community becomes sensitised to the issues and concerned enough about them to lobby hard for regulation.

The rapidity with which the THR "movement" appears to be developing-and the risk associated with allowing the tobacco industry to control its evolution-strongly recommend that the tobacco control community becomes far more familiar with and involved in the issue. The educational process is underway: professional journals are featuring articles on the subject ${ }^{10}$ and conferences increasingly include presentations and debates about THR. More is needed and undoubtedly will occur.

The importance of an informed tobacco control community is highlighted by the just mentioned need to shape and lobby for effective regulation of THR and conventional tobacco products. As well, if THR takes hold, it is possible that it will diminish the role of cessation in the overall field of tobacco control. This will occur if, as a near majority of respondents expects, use of THR products substitutes for cessation. Substitution could mean a change in the market for cessation services, thereby directly affecting the work of many members of the tobacco control community. Similarly, if, as another near majority of respondents anticipates, THR causes children to experiment with novel nicotine containing products, the nature of the challenge confronting prevention specialists may change as well. Given the potential of THR to directly impact their work, mainstream tobacco control professionals have a self interested reason to become familiar with the nature and implications of THR.

The need to better inform and involve the tobacco control community in THR points to a subtle and potentially pernicious consequence, however: attention devoted to THR could divert professionals' time and energy from their current efforts with the cornerstones of tobacco control, prevention, and cessation. One could argue that this is already occurring within a subset of the leadership of tobacco control. ${ }^{9}$ The need to inform and involve the "grassroots" community in THR, while simultaneously avoiding distraction from effective prevention and cessation efforts, constitutes just one more of the many challenges posed by the complex issue of THR. ${ }^{4}$ It is one more challenge to which, collectively, we will have to rise. 


\section{What this paper adds}

A great deal has been written over the past 5-6 years about the public health dilemma created by the introduction of novel nicotine delivery products, many produced by the tobacco industry, that are marketed, implicitly or explicitly, as reducing risk compared to smoking conventional cigarettes. To date, however, no research has evaluated the knowledge, opinions, and beliefs of the "grassroots" tobacco control community concerning "tobacco harm reduction" (THR). This group of professionals and activists undoubtedly will influence the future directions of THR.

Based on a web/mail survey, this study finds that the much of the US tobacco control community has limited knowledge of the THR debate. In general, tobacco control professionals and activists expect THR to grow in importance over time, and to create more risks than benefits to health. They strongly favour government regulation of both THR and conventional tobacco products but do not anticipate passage of legislation requiring regulation in the foreseeable future.

\section{ACKNOWLEDGEMENTS}

This work has been supported by a grant from the Robert Wood Johnson Foundation, Princeton, New Jersey. We thank Paula Lantz for help in developing the survey, eight colleagues for pilot testing it, and Scott Crawford and his colleagues at MSInteractive, Livonia, Michigan, for assistance with execution of the survey and data collection. We also thank two reviewers for helpful suggestions on the original submission.

\section{Authors' affiliations}

K E Warner, E G Martin, Department of Health Management \& Policy, School of Public Health, University of Michigan, Ann Arbor, Michigan, USA

\section{REFERENCES}

1 Kozlowski LT. Harm reduction, public health, and human rights: smokers have a right to be informed of significant harm reduction options. Nicotine \& Tobacco Research 2002;4(suppl 4):55-60
2 Warner KE, Slade J, Sweanor D. The emerging market for long-term nicotine maintenance. JAMA 1997;278:1087-92.

3 Stratton K, Shetty P, Wallace R, et al. Clearing the smoke: assessing the science base for tobacco harm reduction. Washington DC: National Academy Press, 2001.

4 Warner KE. Tobacco harm reduction: promise and perils. Nicotine \& Tobacco Research 2002;4(suppl 2):61-71

5 Mendez D, Warner KE. Adult cigarette smoking prevalence: declining as expected (if not as desired). Am J Public Health (in press).

6 Peto R, Lopez AD. Future worldwide health effects of current smoking patterns. In: Koop CE, Pearson CE, Schwarz MR, eds. Critical issues in global health. New York: Jossey-Bass, 2002:154-61.

7 Warner KE, Peck CC, Woosley RL, et al. Treatment of tobacco dependence: innovative regulatory approaches to reduce death and disease: preface. Food and Drug Law Journal 1998;53(suppl): 1-8.

8 Ferrence R, Slade J, Room R, et al. Nicotine and public health. Washington DC: American Public Health Association, 2000.

9 Martin EG, Warner KE, Lantz PM. Tobacco harm reduction: what do the experts think? Working paper. Ann Arbor, Michigan, USA: Department of Health Management \& Policy, School of Public Health, University of Michigan, 2003.

10 Supplement on harm reduction. Nicotine \& Tobacco Research 2002;4(suppl 2).

11 http://www.spss.com/spssmr/support/mrinterview/faqs/index.htm Accessed 20 May 2003.

12 American Association for Public Opinion Research. Standard definitions: final dispositions of case codes and outcome rates for surveys. Lenexa, Kansas: AAPOR, 2000. http://www.aapor.org/pdfs/ newstandarddefinitions.pdf Accessed 21 May 2003.

13 Henningfield JE, Fagerstrom KO. Swedish Match Company, Swedish snus and public health: a harm reduction experiment in progress? Tobacco Control $2001 ; 10: 253-7$.

14 National Cancer Institute. Risks associated with smoking cigarettes with low machine-measured yields of tar and nicotine. Smoking and Tobacco Control Monograph \#13. U.S. Dept. of Health and Human Services, National Institutes of Health, National Cancer Institute. 2001. http:// cancercontrol.cancer.gov/tcrb/monographs/13/m13 complete.pdf Accessed 17 May 2003.

15 Holbrook J. Tobacco smoking. In: Petersdorf RG, ed. Harrison's principles of internal medicine. New York: McGraw-Hill, 1983:1303-5.

16 Willner JS. Tobacco abuse and dependence. In: Taylor RB, ed. Family medicine 2nd ed. New York: Springer-Verlag, 1983:1662-5.

17 Glantz SA, Slade J, Bero LA, et al. The cigarette papers. Berkeley, California: University of California Press, 1996.

18 Kozlowski LT, Strasser, AA, Giovino GA, et al. Applying the risk/use equilibrium: use medicinal nicotine now for harm reduction. Tobacco Control $2001 \cdot 10 \cdot 201-3$

19 Rodu B. For smokers only: how smokeless tobacco can save your life. New York: Sulzberger \& Graham, 1995.

20 Bates C, Fagerström K, Jarvis MJ, et al. European Union policy on smokeless tobacco: a statement in favour of evidence-based regulation for public health. Tobacco Control 2003;12:360-7.

21 Sweanor DT. Reducing toxicity exposure for the nicotine-dependent. Addiction (in press).

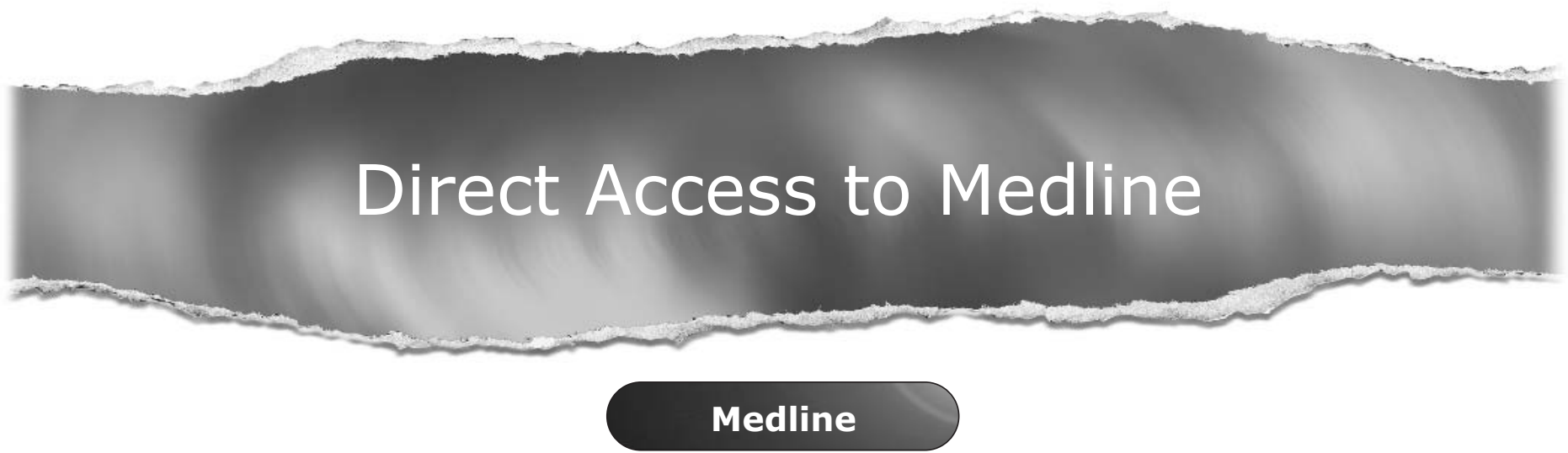

Link to Medline from the homepage and get straight into the National Library of Medicine's premier bibliographic database. Medline allows you to search across 9 million records of bibliographic citations and author abstracts from approximately 3,900 current biomedical journals. 